\title{
HUBUNGAN TINGKAT KEBERSIHAN DIRI DAN FAKTOR PREDISPOSISI PADA ANAK DI PANTI ASUHAN AL-AMAL SURABAYA
}

\author{
Astri Nur Amalia \\ Departemen Promosi Kesehatan dan Ilmu Perilaku \\ Fakultas Kesehatan Masyarakat, Universitas Airlangga \\ E-mail: astri.nur.amalia-2016@fkm.unair.ac.id
}

\begin{abstract}
The incidence of infectious diseases due to personal hygiene in orphanages children often occurs. a factor that has an influence is predisposing factors. The purpose of this study is to know the correlation between the level of personal hygiene and predisposing factors in children at Panti Asuhan Al Amal Surabaya. The research type was observation research with a cross-sectional approach. The research subject's samples used 67 children from 80 children of the total population. Statistical analysis to obtain correlation used chi-square test. The results showed that there is relationship between age ( $p$-value $=0.002)$, knowledge $(p$-value $=0.039)$, and facility $(p$-value $=$ $0,001)$ to the level of personal hygiene. there is no relationship between gender ( $p$-value $=0.084)$ and attitude ( $p$-value $=0.225$ ) to the level of personal hygiene. So it can be concluded that age and knowledge as predisposing factors are dominant to influence a person's behaviour.
\end{abstract}

Keywords: Personal Hygiene, Knowledge, Predisposing Factors, Children

\begin{abstract}
ABSTRAK
Kejadian penyakit menular karena kurangnya kebersihan diri pada anak di panti asuhan sering terjadi. Salah satu faktor yang memiliki pengaruh yaitu faktor predisposisi. Tujuan dari penelitian ini adalah mengetahui hubungan antara tingkat kebersihan diri dan faktor predisposisi pada anak di Panti Asuhan Al-Amal Surabaya. Jenis penelitian ini adalah penelitian observational dengan pendekatan cross-sectional. Jumlah sampel yang digunakan sebesar 67 anak dari total populasi 80 anak. Analisis statistik untuk mendapatkan hubungan menggunakan uji chi-square. Hasil menunjukkan bahwa ada hubungan usia ( $p$-value $=0,002)$, pengetahuan $(p$-value $=0,039)$, dan fasilitas $(p$-value $=0,001)$ terhadap tingkat kebersihan diri. Jenis kelamin $(p$-value $=0,084)$ dan sikap $(p$-value $=0,225)$ tidak ada hubungan terhadap tingkat kebersihan diri. Sehingga dapat disimpulkan bahwa usia, pengetahuan, dan fasilitas sebagai faktor predisposisi yang dominan dalam memengaruhi perilaku seseorang.
\end{abstract}

Kata Kunci: Kebersihan Diri, Pengetahuan, Faktor Predisposisi, Anak

\section{PENDAHULUAN}

Kebersihan diri atau personal hygiene sebagai suatu tindakan untuk memelihara kebersihan dan kesehatan seseorang baik secara fisik maupun psikis. ${ }^{1}$ Kondisi lingkungan panti asuhan sebagai tempat dengan kepadatan penghuni sering dikaitkan dengan masalah kebersihan. Aktivitas penghuni panti asuhan 
memungkinkan terjadinya kontak interpersonal dan pemakaian fasilitas secara bersama, sehingga memudahkan terjadinya penularan penyakit.

Penyakit yang disebabkan karena masalah kebersihan tidak dapat diremehkan. Penyakit kulit merupakan jenis penyakit yang paling sering terjadi dalam masalah kebersihan diri. Lebih dari $60 \%$ dalam suatu populasi pernah mengalami setidaknya satu jenis penyakit kulit, khususnya pada golongan usia anak. Anak merupakan kelompok yang rentan disebabkan masih dalam tahap perkembangan imunitas. Dampak penyakit kulit pada anak dapat mengakibatkan distabilitas dan gangguan estetika yang akhirnya berpengaruh pada tumbuh kembang dari segi kejiwaan. ${ }^{2}$

Kesehatan fisik dan psikis sangat dibutuhkan untuk membantu perkembangan anak. Tugas orang tua untuk mengantarkan perkembangan anak, namun bila ada alasan dan aturan hukum yang membuat adanya pemisahan pengasuhan pada orang tua maka pengasuhan dialihkan kepada pengasuh alternatif. ${ }^{3}$

Anak yang berada di panti asuhan merupakan bentuk dari bantuan pengasuhan dalam pengasuh alternatif. Kebutuhan fisik dan psikis anak di panti asuhan bergantung pada pengasuh yang berperan sebagai keluarga pengganti. ${ }^{4}$ Maka sudah menjadi tugas pengasuh di panti asuhan juga untuk membantu anak dalam menjaga, merawat, dan mengatasi masalah kebersihan dirinya.
Bantuan pengasuhan dari pengasuh panti asuhan akan membantu anak dalam menanamkan nilai-nilai kehidupan yang akhirnya dapat membentuk sikap anak. Menurut Green, terbentuknya suatu perilaku dapat dipengaruhi oleh faktor-faktor predisposisi. ${ }^{4}$

Faktor-faktor predisposisi yang sering dikaitkan dengan tingkat kebersihan diri anak di panti asuhan diantara-nya yaitu pengetahuan, sikap, dan fasilitas. Pengetahuan sebagai parameter anak dalam mengetahui, memahami, dan mampu menganalisis suatu masalah. Pengetahuan juga sebagai salah satu domain dari perilaku. Sedangkan sikap sebagai suatu tanggapan anak terhadap suatu situasi, sehingga sikap juga menjadi salah satu dari domain perilaku. $^{5}$

Fasilitas merupakan faktor yang memiliki pengaruh dalam menentukan tingkat kebersihan diri anak asuh. Adanya sarana penunjang untuk melakukan aktivitas kebersihan diri sangat membantu anak di panti asuhan untuk mempertahankan kesehatannya. ${ }^{6}$ Berdasarkan penjelasan tersebut, maka peneliti ingin mengetahui adanya hubungan antara tingkat kebersihan diri dengan faktor predisposisi pada anak di panti asuhan Al- Amal Surabaya.

\section{METODE PENELITIAN}

Penelitian ini merupakan penelitian observasional dengan pendekatan crosssectional. Jenis penelitian ini hanya menganalisis hubungan antara variabel 
dependen dan independen. Variabel dependen dalam penelitian ini yaitu kejadian masalah personal higiene, sedangkan variabel independen yaitu faktor predisposisi yang terdiri dari jenis kelamin, usia, pendidikan, pengetahuan, sikap, dan fasilitas panti asuhan.

Populasi yang menjadi subjek penelitian adalah anak asuh di panti asuhan Al-Amal Surabaya sejumlah 80 anak. Besar sampel yang digunakan menurut perhitungan rumus Slovin yaitu 67 anak. Data yang digunakan adalah data primer melalui lembar kuesioner. Prosedur pengambilan data meliputi: (1) menyampaikan tujuan, manfaat, dan prosedur penelitian kepada kepala panti asuhan, (2) meminta persetujuan penelitian kepada kepala panti asuhan, (3) menjelaskan tujuan dan manfaat penelitian kepada anak asuh, (4) meminta anak asuh memberikan persetujuan melalui surat persetujuan atas sepengetahuan dan tanda tangan wali asuh, (5) melakukan pengambilan data dengan membagikan kuesioner.

Seluruh data penelitian diolah menggunakan aplikasi olah data statistik. Uji statistik yang digunakan yaitu Chi-Square dengan derajat kesalahan 5\%. Syarat pada uji Chi-Square harus terpenuhi, kemudian hasil analisis dijelaskan dengan deskriptif.

\section{HASIL DAN PEMBAHASAN}

\section{Tingkat Kebersihan Diri Anak Asuh}

Kebersihan diri bertujuan untuk mencegah penyakit, meningkatkan status kesehatan, dan memelihara kebersihan. Potter (2010) menjelaskan bahwa pemeliharaan kebersihan diri meliputi kebersihan kulit, rambut, gigi, mulut, telinga, tangan, kaki, dan kuku. $^{7}$

Masalah kebersihan diri dapat dilihat dari intensitas penyakit yang berkaitan dengan kebersihan. Pada penelitian ini, tingkat kebersihan diri dikategorikan berdasarkan jumlah kejadian penyakit yang pernah dialami akibat lalai terhadap kebersihan diri selama tinggal di panti asuhan. Berikut jenis masalah atau penyakit terkait kebersihan diri yang terjadi pada anak asuh di Panti Asuhan Al-Amal Surabaya:

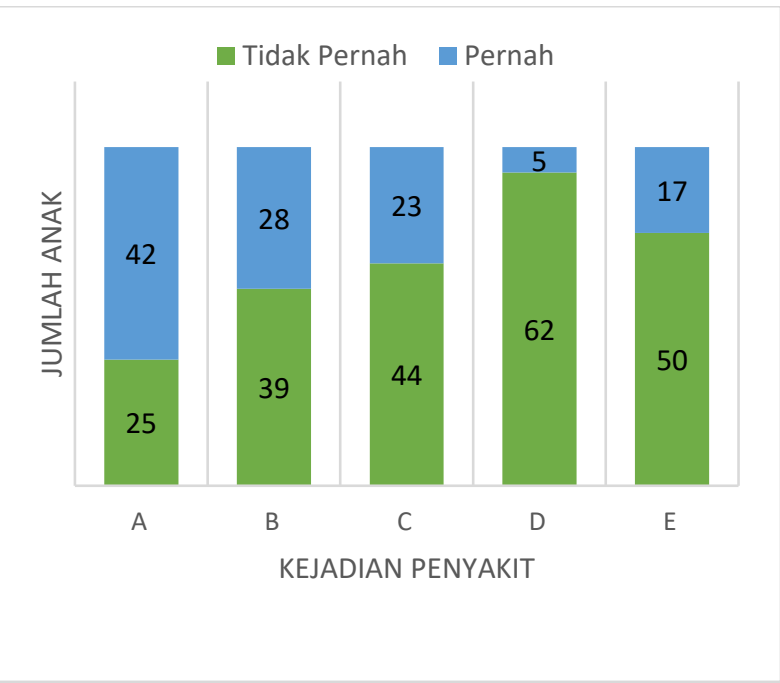

Gambar 1. Kejadian Penyakit

$$
\begin{array}{ll}
\text { Keterangan } & \mathrm{A}=\text { Kulit } \\
& \mathrm{B}=\text { Rambut } \\
\mathrm{C}=\text { Gigi dan Mulut } \\
\mathrm{D}=\text { Telinga } \\
\mathrm{E}=\text { Tangan dan Kaki }
\end{array}
$$

Gambar 1, menandakan setiap anak pernah mengalami penyakit akibat lalai kebersihan dengan jumlah lebih dari 1 jenis penyakit. 
Mayoritas seluruh anak pernah mengalami penyakit kulit yaitu dermatitis, rasa gatal yang lama, panu, kudis dan kurap. Jenis penyakit tertinggi kedua yaitu masalah kebersihan rambut seperti ketombe, kutu rambut, dan kulit rambut gatal. Urutan ketiga penyakit pada tangan, kaki, dan kuku yaitu kapalan (callus) dan gejala infeksi jamur (tinea pedis). ${ }^{8}$

Minoritas pernah mengalami penyakit telinga yaitu infeksi telinga. Infeksi telinga dapat menyebabkan bakteri berkembang biak di telinga. Meskipun infeksi telinga sangat jarang terjadi, namun dapat mengganggu aktivitas pendengaran dan keseimbangan tubuh. ${ }^{9}$
Berdasarkan kejadian penyakit, tingkat kebersihan diri anak dikategorikan menjadi cukup baik dan kurang baik (Gambar 2). Kategori cukup baik untuk intensitas 1-3 kali kejadian penyakit dan kategori kurang baik untuk intensitas lebih dari 3 kali kejadian penyakit selama tinggal di panti asuhan.

Hasil berdasarkan pembagian kategori tingkat kebersihan diri menunjukkan bahwa tingkat kebersihan diri anak asuh di Panti Asuhan Al-Amal dominan cukup baik, namun tetap saja masalah kebersihan tidak boleh diabaikan karena dapat mengganggu pertumbuhan dan perkembangan anak.

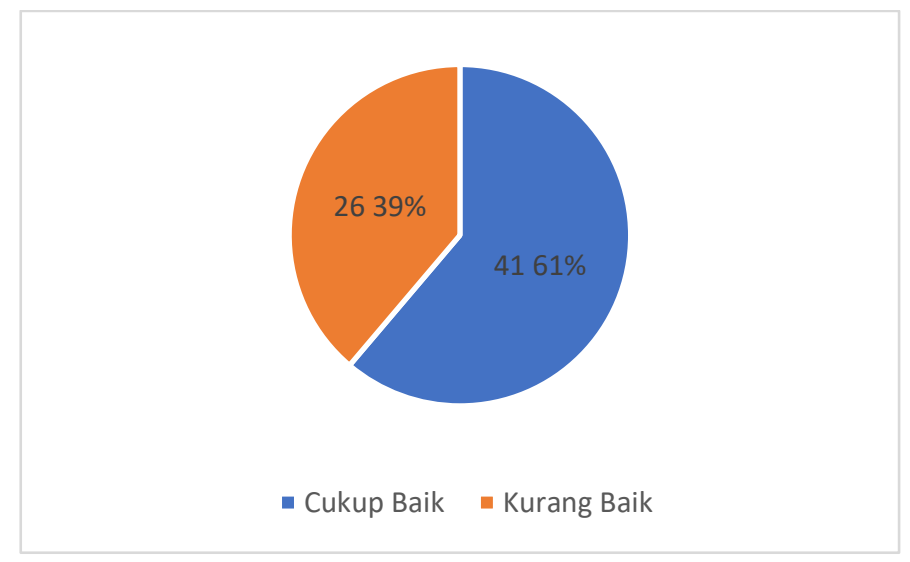

Gambar 2. Tingkat Kebersihan Diri

Tabel 1. Hasil Analisis Data dengan Uji Chi-Square antara Tingkat Kebersihan Diri dan Faktor Predisposisi pada Anak Asuh di Panti Asuhan Al-Amal Surabaya.

\begin{tabular}{|c|c|c|c|c|c|}
\hline \multirow[t]{3}{*}{ Variabel } & \multicolumn{2}{|c|}{ Tingkat Kebersihan diri } & \multirow[t]{2}{*}{ Total } & \multicolumn{2}{|c|}{ Hasil uji Chi-Square } \\
\hline & Cukup Baik & Kurang Baik & & \multirow{2}{*}{ P-Value } & \multirow{2}{*}{ Interpretasi } \\
\hline & $\mathrm{n}(\%)$ & $\mathrm{n}(\%)$ & $\mathrm{n}(\%)$ & & \\
\hline \multicolumn{6}{|l|}{ Jenis Kelamin } \\
\hline Perempuan & $10(14,9 \%)$ & $21(31,3 \%)$ & $31(46,3 \%)$ & 0,084 & Tidak ada hubungan \\
\hline Laki-laki & $20(29,9 \%)$ & $15(23,9 \%)$ & $36(53,7 \%)$ & & \\
\hline \multicolumn{6}{|l|}{ Usia } \\
\hline Anak & $18(26,9 \%)$ & $8(11,9 \%)$ & $26(38,8 \%)$ & 0,002 & Ada hubungan \\
\hline Remaja Awal & $12(17,9 \%)$ & $29(43,3 \%)$ & $41(61,2 \%)$ & & \\
\hline
\end{tabular}




\begin{tabular}{|c|c|c|c|c|c|}
\hline \multirow[t]{3}{*}{ Variabel } & \multicolumn{2}{|c|}{ Tingkat Kebersihan diri } & \multirow[t]{2}{*}{ Total } & \multicolumn{2}{|c|}{ Hasil uji Chi-Square } \\
\hline & Cukup Baik & Kurang Baik & & \multirow{2}{*}{ P-Value } & \multirow{2}{*}{ Interpretasi } \\
\hline & $\mathrm{n}(\%)$ & $\mathrm{n}(\%)$ & $\mathrm{n}(\%)$ & & \\
\hline \multicolumn{6}{|l|}{ Pengetahuan } \\
\hline Kurang Baik & $6(9,0 \%)$ & $13(19,4 \%)$ & $19(28,3 \%)$ & \multirow{3}{*}{0,039} & \multirow{3}{*}{ Ada hubungan } \\
\hline Cukup Baik & $22(32,8 \%)$ & $16(23,9 \%)$ & $38(56,7 \%)$ & & \\
\hline Baik & $2(3,0 \%)$ & $8(11,9 \%)$ & $10(14,9 \%)$ & & \\
\hline \multicolumn{6}{|l|}{ Sikap } \\
\hline Cukup Baik & $17(25,4 \%)$ & $15(22,4 \%)$ & $32(47,8 \%)$ & \multirow[t]{2}{*}{0,225} & \multirow[t]{2}{*}{ Tidak Ada hubungan } \\
\hline Baik & $13(19,4 \%)$ & $22(32,8 \%)$ & $35(52,2 \%)$ & & \\
\hline \multicolumn{6}{|l|}{ Fasilitas } \\
\hline Kurang Baik & $7(10,4 \%)$ & $5(7,5 \%)$ & $12(17,9 \%)$ & \multirow{3}{*}{0,001} & \multirow{3}{*}{ Ada hubungan } \\
\hline Cukup Baik & $7(10,4 \%)$ & $26(38,8 \%)$ & $33(49,3 \%)$ & & \\
\hline Baik & $16(23,9 \%)$ & $6(9,0 \%)$ & $22(32,8 \%)$ & & \\
\hline
\end{tabular}

\section{Jenis Kelamin}

Jenis kelamin merupakan perbedaan berdasarkan fungsi biologis yang melekat pada seseorang sejak lahir. Perbedaan jenis kelamin dapat membentuk perbedaan pendapat, namun tidak bisa menentukan perilaku seseorang. ${ }^{10}$ Berdasarkan Tabel 1, mayoritas subjek penelitian adalah laki-laki. Hasil uji chi-square dengan $p$-value $0,084>0,05$ maka dapat diartikan tidak ada hubungan antara tingkat kebersihan diri dan jenis kelamin anak asuh dari Panti Asuhan Al-Amal Surabaya. Pada tabel 1 juga dapat diketahui bahwa tidak ada perbedaan signifikan tingkat kebersihan diri antara laki-laki dan perempuan.

Hasil ini bertentangan dengan hasil penelitian Zakiudin (2016), yang menunjukkan hasil ada hubungan antara jenis kelamin dengan perilaku kebersihan diri ( $p$-value $=0,000)$ santri di Pondok Pesantren di wilayah Kabupaten Brebes. ${ }^{11}$ Naftassa (2018) menjelaskan bahwa ada hubungan antara jenis kelamin terhadap kejadian skabies $(p$-value $=0.009)$ pada santri pondok pesantren Qotrun Nada Kota Depok. ${ }^{12}$

Perbedaan biologis pada jenis kelamin memungkinkan adanya perbedaan perilaku dalam menjaga dan merawat diri, namun kejadian penularan penyakit tidak memandang jenis kelamin tertentu. ${ }^{10}$ Dalam penelitian ini, tidak ada perbedaan signifikan antara laki-laki maupun perempuan terhadap tingkat kebersihan diri karena hampir seluruh anak menyatakan pernah mengalami masalah atau penyakit yang berkaitan dengan kebersihan diri.

\section{Usia}

Berdasarkan Tabel 1, mayoritas usia responden pada kategori remaja awal yaitu 1216 tahun $^{13 .} \quad$ Hasil uji chi-square dengan $p$ value $0,002<0,05$ dapat diartikan ada hubungan antara usia dan tingkat kebersihan diri. Berbeda dengan pendapat Bujawati (2016) yang menjelaskan tidak ada pengaruh usia dengan personal hygiene selama menstruasi di Ponpes Babul Khaer Kabupaten Bulukumba. ${ }^{14}$ 
Masa remaja awal atau masa anak-anak akhir menguasai keterampilan dasar membaca, menulis, aritmatika, dan secara formal mulai mengenal lingkungan beserta dengan budayanya, serta mulai terbentuk kontrol diri. ${ }^{15}$ Berdasarkan penjelasan santrock dapat diketahui pada masa perkembangan anak, ada proses belajar dan membangun nilai-nilai dari kehidupan sehari-hari, sehingga dalam peningkatan usia terjadi pembentukan perilaku termasuk perilaku kebersihan diri.

\section{Pengetahuan}

Berdasarkan Tabel 1, mayoritas pengetahuan responden tentang kebersihan diri cukup baik, hasil chi-square dengan nilai $p$ value $0,039<0,05$ sehingga dapat diartikan bahwa ada hubungan tingkat kebersihan diri dan pengetahuan anak asuh di panti asuhan Al-Amal Surabaya.

Hasil ini sejalan dengan Fatima (2018) yang menyatakan bahwa ada hubungan pengetahuan dengan tingkat aktivitas personal hygiene $(p$-value $=0,008)$ lansia. ${ }^{16}$ Pratama (2017) menjelaskan bahwa pengetahuan yang kurang menjadikan anak tidak perhatian terhadap pentingkan kebersihan diri sehingga meningkatkan risiko penyebaran penyakit menular. ${ }^{17}$

\section{Sikap}

Sikap merupakan respon seseorang terhadap suatu peristiwa. Sikap sebagai kesiapan atau kesediaan seseorang untuk melakukan tindakan, sehingga sikap merupakan perilaku tertutup. ${ }^{5}$ Pada Tabel 1, mayoritas sikap anak baik dan diketahui hasil uji chi-square dengan $p$ value 0,225 > 0,05 yang berarti bahwa tidak ada hubungan sikap dengan tingkat kebersihan diri anak di Panti Asuhan Al-Amal Kota Surabaya. Sejalan dengan hasil Novaria (2016) yang menyatakan bahwa tidak ada pengaruh dari faktor sikap terhadap pemeliharaan kebersihan gigi dan mulut $(p$-value $=0,163)$ pada anak Agape Sikumana Kota Kupang. ${ }^{18}$

Suatu sikap belum tentu menghasilkan suatu tindakan. Sehingga sikap merupakan kesiapan dan pertimbangan seseorang dalam bertindak. Maka dalam penelitian ini, sikap tidak dapat menentukan tingkat kebersihan diri.

\section{Fasilitas}

Fasilitas merupakan sarana pendukung seseorang untuk dapat melakukan tindakan. Sehingga fasilitas yang dibutuhkan bagi setiap orang. Berdasarkan Tabel 1, diketahui mayoritas fasilitas pendukung kebersihan diri di panti asuhan cukup baik. Hasil p-value 0,001 <0,05 yang berarti ada hubungan antara fasilitas dan tingkat kebersihan diri anak di panti asuhan AlAmal Surabaya.

Fasilitas yang tersedia di dalam panti asuhan berdasarkan pernyataan anak dalam data primer sebagai berikut:

1. Mayoritas $45(67,2 \%)$ anak menyatakan sering tersedia air bersih yang bening dan tidak berbau untuk kegiatan kebersihan diri. 
2. Mayoritas $60(89,6 \%)$ anak menyatakan selalu tersedia alat mandi sesuai masingmasing kebutuhan anak.

3. Mayoritas $58(86,6 \%)$ anak menyatakan selalu tersedia alat untuk membersihkan kamar mandi.

4. Mayoritas $62(92,5 \%)$ anak menyatakan sering tersedia alat untuk mencuci pakaian.

5. Mayoritas $48(71,6 \%)$ anak menyatakan sering tersedia alat untuk membersihkan rumah.

6. Mayoritas $42(62,7 \%)$ anak menyatakan tersedia jamban yang bersih dan tidak berbau.

7. Mayoritas $43(64,2 \%)$ anak menyatakan pernah atau kadang obat-obatan untuk pertolongan terhadap kejadian penyakit.

Berdasarkan data primer tersebut, dapat diketahui jika ketersediaan air dan alat-alat kebersihan diri sudah baik. Sesuai dengan pernyataan Friska (2017) yang menyatakan bahwa ketersediaan fasilitas dan lingkungan fisik rumah berhubungan dengan gangguan kulit. $^{19}$

Ada fasilitas di panti asuhan yang masih kurang dalam membantu aktivitas kebersihan diri khususnya ketersediaan jamban sehat dan obat-obatan untuk pertolongan awal. Ketersediaan air dan jamban sehat merupakan sanitasi dasar yang wajib terpenuhi dalam persyaratan kesehatan perumahan. Indikator air yang layak digunakan adalah air yang bening, tidak berwarna, tidak berbau, dan memenuhi minimal standar dari bakteri patogen. Jamban yang sehat adalah jamban yang memiliki septic tank sehingga terjadi dekomposisi, keadaan jamban bersih, dan tidak terkontaminasi air. ${ }^{20}$

Lingkungan fisik dan semua fasilitas, serta pelayanan sangat berguna untuk kesehatan jasmani, rohani, dan keadaan sosial yang baik untuk keluarga dan individu. Rumah sehat merupakan salah satu sarana untuk mencapai derajat kesehatan yang optimal. ${ }^{21}$

\section{SIMPULAN DAN SARAN}

\section{Simpulan}

Simpulan dari penelitian ini yaitu mayoritas responden berjenis kelamin anak lakilaki sejumlah $36(53,7 \%)$, usia remaja awal sejumlah $41(61,2 \%)$, memiliki pengetahuan sebesar 38 (56,7\%) anak cukup baik, sikap baik sebanyak $35(52,2 \%)$ anak. Mayoritas responden menilai fasilitas yang tersedia dari panti asuhan sebesar $33(49,3 \%)$ anak menyatakan cukup baik. Tidak ada hubungan antara jenis kelamin dengan tingkat kebersihan diri anak. Ada hubungan antara usia dengan tingkat kebersihan diri anak. Ada hubungan antara pengetahuan dengan tingkat kebersihan diri anak. Tidak Ada hubungan antara sikap dengan tingkat kebersihan diri anak. Ada hubungan antara fasilitas dengan tingkat kebersihan diri anak.

\section{Saran}

Sebaiknya pengurus panti asuhan lebih memperhatikan masalah kebersihan diri bagi anak dengan melakukan upaya promosi 
kesehatan sehingga dapat meningkatkan pengetahuan dan sikap anak terhadap kesehatan. Sebaiknya anak di panti asuhan lebih peduli dalam menjaga dan merawat kebersihannya.

\section{REFERENSI}

1. Wartonah T. Kebutuhan Dasar Manusia dan Proses Keperawatan. Jakarta: Salemba Medika;

2. WHO. Epidemiology and management of common skin disease in children in developing countries. 2009;

3. Kementerian Sosial RI. Standar Nasional Pengasuhan Untuk Lembaga Kesejahteraan Sosial Anak. Jakarta: Kementerian Sosial Republik Indonesia; 2011.

4. Kementerian Agama RI. Pedoman Lembaga Yatim Piatu. Jakarta: Kementerian Agama Republik Indonesia. 2010;

5. Soekidjo N. Promosi Kesehatan dan Perilaku Kesehatan. Jakarta: Rineka Cipta; 2012.

6. Dian H. Pemenuhan Kebutuhan Dasar Anak Oleh Panti Sosial Asuhan Anak (PSAA). Bandung: Jurnal Universitas Padjadjaran; 2015.

7. Potter, P.A dan Perry AG. Buku Ajar Fundamental Keperawatan: Konsep, Proses, dan Praktik Alih Bahasa, Renata Komalasari. Jakarta: EGC;

8. Djuanda A. Ilmu Penyakit Kulit dan Kelamin. Jakarta: Badan Penerbit Fakultas Kedokteran UI; 2017.

9. FKUI. Buku Ajar Ilmu Kesehatan: Telinga, Hidung, Tenggorokan (Edisi 7). Jakarta: Fakultas Kesehatan Universitas Airlangga Press;

10. Noor N. N. Pengantar Epidemiologi Penyakit Menular. Jakarta: Rineka Cipta; 2006.

11. Zakiudin A. Perilaku Kebersihan Diri Santri
Pondok Pesantren Wilayah Kabupaten Brebes Akan Terwujud Jika Didukung Dengan Ketersediaan Sarana Prasarana. Semarang: Jurnal Promosi Kesehatan Indonesia.; 2016.

12. Naftassa Z. Hubungan Jenis Kelamin, Tingkat Pendidikan, dan Pengetahuan Terhadap Kejadian Skabies Pada Santri Pondok Pesantren Qotrun Nada Kota Depok. J Biomedika. 2018;

13. Depkes RI. Profil Kesehatan Indonesia. Jakarta: Departemen Kesehatan Republik Indonesia; 2009.

14. Bujawati E. Faktor-Faktor yang Berhubungan Sengan Personal Hygiene Selama Menstruasi Pada Santriwati Pesantren Babul Khaer Kebupaten Bulukumba Provinsi Sulawesi Selatan. J Kesehat Masy UIN Alauddin. 2016;

15. Santrock J. Masa Perkembangan Anak. Jakarta: Salemba Humanika; 2013.

16. Fatima OR De. Hubungan Pengetahuan Tentang Kebersihan Diri Dengan Tingkat Kemandirian Melakukan Aktivitas Personal Hygiene Lansia. J Keperawatan Poltekkes Kemenkes Malang. 2018;

17. Pratama TS. Pengetahuan, Sikap, Kebersihan Personal dan Kebiasaan Pada Santri Penderita Penyakit Skabies Di Pondok Pesantren. J Univ Muhammadiyah. 2017;

18. Novaria M. Identifikasi Faktor yang Mempengaruhi Perilaku Anak Dalam Pemeliharaan Kebersihan Gigi dan Mulut: Studi Pada Pusat Pengembangan Anak Agape Sikumana Kota Kupang, Nusa Tenggara Timur, Indonesia. J Kedokt Gigi Univ Gajah Mada. 2016;

19. Friska K. Hubungan Personal Hygiene, Sanitasi Dasar dan Faktor Lingkungan Fisik Rumah Dengan Gangguan Kulit Pemulung di TPA Kenep Kabupaten Pasuruan. Surabaya: Universitas Airlangga Press; 2017.

20. Menkes RI. Menkes RI., 1999. Persyaratan Kesehatan Rumah Dalam Keputusan 
Menteri Kesehatan Republik Indonesia Nomor 829/MENKES/SK/VII/1999. Jakarta: Menteri Kesehatan Republik Indonesia. Jakarta: Menteri Kesehatan Republik Indonesia; 1999.

21. WHO. Guidelines For Healthy Housing. 1999; Available from: https://apps.who.int/iris/bitstream/handle/1 0665/191555/EURO_EHS_31_eng.pdf;jses sionid=3A2F44A9E5538CB2B619D18F53 DA31DB? sequence $=1$ diakses 1 Februari 2018 